\title{
UMA MODALIDADE PECULIAR DE PRIVATIZAÇÃO DA EDUCAÇÃO PÚBLICA: A AQUISIÇÃO DE “SISTEMAS DE ENSINO” POR MUNICÍPIOS PAULISTAS
}

\author{
THeresa Adriāo* \\ TeIse Garcia ${ }^{* *}$ \\ RAQUEL BORGHI ${ }^{* * *}$ \\ LISETE ARELARO ${ }^{* * * *}$
}

\begin{abstract}
RESUMO: Este artigo trata da tendência de crescimento das parcerias, pela via dos contratos, entre os municípios paulistas e empresas privadas da área educacional para a aquisição de "sistemas apostilados de ensino". Os dados referem-se a levantamento desenvolvido no âmbito da pesquisa "Estratégias municipais para a oferta da educação básica: uma análise de parcerias público-privadas no estado de São Paulo", financiada pela FAPESP. No período destacado neste trabalho, 1990 a 2007, percebe-se a ampliação deste tipo de relação acentuadamente nos municípios com até 50 mil habitantes. Tal percepção confirma hipótese de incremento da dependência das esferas municipais junto ao setor privado, na medida em que os municípios têm ampliadas suas responsabilidades para com a oferta e a manutenção da educação básica, sem a prévia organização técnico-política do aparato de gestão local.
\end{abstract}

Palavras-chave: Parceria público-privada. Sistema apostilado de ensino. Municipalização

\footnotetext{
* Doutora em Educação e professora do Instituto de Biociências da Universidade Estadual Paulista (UnEsp, Rio Claro). E-mail: theadriao@yahoo.com.br

** Doutora em Educação e professora da Faculdade de Filosofia, Ciências e Letras da Universidade de São Paulo (USP, Ribeirão Preto). E-mail: teise@ffclrp.usp.br

*** Doutora em Educação e professora do Instituto de Biociências da UNESP (Rio Claro). E-mail: rborghi@rc.unesp.br

**** Doutora em Educação e professora do Departamento de Administração Escolar e Economia da Educação, da Faculdade de Educação da Usp. E-mail: liselaro@usp.br
} 
Uma modalidade peculiar de privatização da educação pública...

A PECULIAR MODALITY TO PRIVATIZE PUBLIC EDUCATION: the acQuisition of “education systems” by São Paulo cities

ABSTRACT: This paper discusses the growing tendency of partnership, through contracts, between cities of the state of São Paulo and private educational companies, which sells them "education systems". Data refer to a research developed under the "Research Strategies for the Municipal Provision of Basic Education: an Analysis of Public-Private Partnerships in the State of São Paulo", funded by FAPESP. Between 1990 and 2007, we note a marked expansion of this kind of relationship in cities with less than 50.000 inhabitants. This confirms the hypothesis of their dependence on the private sector. They have widened their responsibilities to supply and maintain basic education, but have not organized their local management technically and politically.

Key words: Public-private partnership. Education systems. Municipality.

\section{Introdução}

A

s parcerias entre as administraçôes municipais e o setor privado para a consecução da oferta educacional tem se disseminado no Brasil nos últimos anos, conforme atestam vários estudos (Cury, 2002; Peroni, 2003; Arelaro, 2008; Adrião \& Borghi, 2008).

Esta relação, em si, não constitui novidade, se nos detivermos nas esferas educativas, nas quais tradicionalmente o poder público delegou à iniciativa privada a tarefa de atender à demanda, como é o caso da educação especial (Pietro \& Sousa, 2007) e das creches (Campos, 1998; Correa, 2007), ou ainda se considerarmos a tradição liberal que permite a coexistência de oferta pública e privada em todas as etapas de escolaridade (Cury, 2005). Todavia, consideramos que o processo de delegação de responsabilidades do setor público para o privado, por meio do aumento da presença deste último na consecução de políticas para a educação pública, na etapa de escolaridade obrigatória, ampliase no final do século $\mathrm{xx}$, generalizando-se para muito além de modalidades específicas, a partir da profunda reforma do Estado brasileiro, posta em curso na década de 1990 (Leher, 2003; Adrião \& Peroni, 2005; Oliveira, 2000; Vieira, 2000; Krawczyk, 2000; Dourado, 2007, entre outros). 
Nesse contexto, as perspectivas descentralizadoras, em geral, para esferas subnacionais (Farah, 2001) impuseram a esses níveis de governo tarefas e atribuições que exigem, para além do repasse de recursos, condições de elaboração e implantação de políticas públicas. Como resposta a essas novas demandas, complexificadas pela diminuição dos aparatos técnicos, em virtude das reformas na administração pública ocorridas durante os anos de 1990, apresentam-se as parcerias com empresas privadas.

No estado de São Paulo, proliferam opções governamentais com vistas a implementar tais parcerias no campo educacional, sobretudo a partir da municipalização do ensino fundamental, iniciada no estado em 1996 e, posteriormente, implementada em nível nacional, após a criação do Fundo de Manutenção e Desenvolvimento do Ensino Fundamental e Valorização do Magistério (FUNDEF), por meio da Emenda Constitucional n. 14/96.

Este trabalho, resultante de pesquisa interinstitucional, ${ }^{1}$ detémse na análise de uma modalidade peculiar dessas parcerias: aquelas firmadas entre o poder público local e empresas privadas stricto sensu, isto é, com fins lucrativos, para a compra do que se dissemina como "sistemas de ensino". Entendemos que essa compra representa mais do que a simples aquisição de materiais didáticos, dado se tratar de estratégia por meio da qual o setor privado amplia seu mercado, ao incidir sobre o espaço público na mesma medida em que o setor público transfere parcela de suas responsabilidades para com a educação à iniciativa privada.

Por essa razão, não nos parece acaso a adoção da denominação "sistema de ensino" por parte das empresas que oferecem seus produtos educacionais. Para Dermeval Saviani, a implicação do termo sistema, quando de sua adoção no campo educacional, pressupõe opção coordenada e integrada de partes em "um todo que articula uma variedade de elementos que, ao se integrarem ao todo, nem por isso perdem a própria identidade" (Saviani, 1997, p. 206).

A análise aqui apresentada pauta-se em dados obtidos diretamente de representantes de gestores municipais ou de secretarias municipais de educação dos 645 municípios paulistas, organizados em função do porte dos municípios, tendo em vista sua população e as empresas contratadas. O período abordado na pesquisa compreendeu os anos de 1997 
Uma modalidade peculiar de privatização da educação pública...

a 2006. Complementarmente, desenvolveram-se estudos de caso em sete municípios de portes diversos que adquiriram sistemas apostilados.

As informações coletadas indicam uma tendência crescente nos municípios paulistas, sobretudo naqueles com até 50 mil habitantes, considerados de pequeno porte, a buscar suporte político e pedagógico para o atendimento educacional sob sua responsabilidade junto a empresas privadas que oferecem serviços e produtos, tais como materiais didáticos para alunos e professores, incluindo apostilas e CDROMs, formação docente em serviço e monitoramento do uso dos materiais adquiridos. Parece-nos que tais empresas, mais do que meras fornecedoras de materiais e equipamentos, passam a incidir sobre o desenho da política educacional local e sobre a organização do trabalho docente e administrativo desenvolvido em cada uma das unidades de ensino da rede pública, razão pela qual se tornam parceiras dos governos municipais. O termo parceria é adotado aqui de acordo com Bezerra (2008, p. 62-63):

(...) A expressão parceria púbico-privada (...) implica também na capacidade de intervenção que o setor privado passa a dispor junto à administração pública, por meio da assunção total ou parcial de responsabilidades até então atribuídas ao poder público em sua totalidade.

Acreditamos, também, que a análise das relações entre os setores público e privado não pode se limitar à sua caracterização jurídica, ainda que este aspecto não deva ser negligenciado. É o conjunto de responsabilidades compartilhadas ou transferidas do setor público para a instituição privada, bem como a centralidade das atividades previstas nesta transferência para a consecução de políticas públicas que consubstanciam a natureza da parceria. Por esse motivo, no caso aqui destacado, acredita-se que, para além de mera aquisição de apostilas ou cursos pelos governos municipais, trata-se da transferência para a esfera privada da função de elaboração e operacionalização de política pública até então exercida pela esfera pública estatal.

Em resumo, pretendemos refletir sobre as razões, as estratégias e as limitações decorrentes de acordos entre o poder público municipal e determinadas empresas privadas para a oferta de serviços educacionais. Para tanto, o texto se organiza em três partes: na primeira, mapeia-se a relação entre os municípios e as empresas privadas; na segunda, a partir 
de dados de entrevistas com gestores municipais e representantes das empresas, indica-se e analisa-se as motivaçôes para que as parcerias se estabeleçam e, por fim, apresenta-se considerações sobre a inserção da lógica privada na escola pública.

A educação municipal paulista frente à sedução da iniciativa privada: delineando o problema

Temos como pressuposto que a implementação de parcerias entre a esfera pública, entendida como estatal, e a privada é uma das estratégias para a reforma do Estado implantada no país a partir dos anos de 1990, a qual, como resposta a uma suposta crise de eficácia da administração pública, propōe a adoção da administração gerencial (Bresser Pereira, 1996, Bresser Pereira \& Spink, 1998). Também consideramos que tal tendência de consolidação de parcerias/convênios entre municípios paulistas e a iniciativa privada relaciona-se aos processos de descentralização da educação pública paulista, cuja principal medida foi a municipalização do ensino fundamental, em especial de suas séries iniciais, introduzida no estado de São Paulo, mais enfaticamente a partir de 1996, na primeira Gestão Mario Covas (1995-1998) (Adrião, 2001; Arelaro, 1999; Ganzeli \& Oliveira, 2001; Martins, 2003).

Da articulação dessas duas orientações complementares, municipalização do ensino fundamental e alteraçoos no padrão de intervenção estatal, resultaram inúmeros arranjos político-institucionais forjados pelas administrações municipais paulistas para, na melhor das hipóteses, responder às demandas educativas assumidas. Num quadro de despreparo técnico e escassez de recursos, identificados por Barreto (1988) desde os anos de 1980, uma das consequências das opções governamentais parecem apontar para a introdução de mecanismos de privatização da educação municipal.

Tal situação, ao mesmo tempo em que reflete as dificuldades enfrentadas pelas administrações municipais, apresenta-se como justificativa para a opção de políticas governamentais que se apóiam na esfera privada, subvencionando-a, em troca da transferência da lógica de organização privada para o setor público, ao invés de reverter esses recursos públicos para a melhoria e/ou consolidação do aparato 
Uma modalidade peculiar de privatização da educação pública...

governamental necessário à manutenção e ao desenvolvimento do ensino. A esse respeito são pertinentes as observaçôes de Carlos Jamil Cury:

A rigor, as políticas de descentralização, sobretudo se acompanhadas do atual modo vigente do pacto federativo, significam um repasse de responsabilidade dos escalóes nacionais para os subnacionais. Se estes últimos não forem capazes de sustentar suas responsabilidades, o risco é o de haver um deslocamento do público para o privado e aí reside o risco maior de uma competitividade e seletividade, de corte mercadológico, pouco natural aos fins da educação. (Cury, 2001, p. 196)

É no contexto, sinteticamente apresentado, que se generaliza em São Paulo a compra de "sistemas de ensino", como uma das expressóes de subvenção pública à esfera privada no campo educacional. No ano de 2007, a revista Veja (on-line), em matéria intitulada "Escola pública, gestão particular", caracterizava esta simbiose como um "novo modelo" de administração da educação. À época, a revista indicava 145 municípios paulistas nos quais a parceria com empresas privadas fora estabelecida, implicando a compra de materiais didáticos e consequente assessoria para o emprego dos mesmos. Em alguns casos, o "pacote" adquirido incluía sistemáticas de avaliação de desempenho de estudantes e professores.

É sugestivo que a matéria remeta a um suposto ganho de qualidade para a escola pública, por meio da "gestão privada" (Antunes, 2005). Frise-se, no entanto, que a matéria nada informava sobre a qualidade da educação municipal existente antes da adoção do referido sistema. O município de Porto Feliz, indicado como exemplo na reportagem, encontrava-se, desde 2005, entre os 70 municípios brasileiros com melhor Índice de Responsabilidade Social (IRS), cujo cálculo agrega informações relativas à qualidade da educação e da saúde, o cumprimento da Lei de Responsabilidade Fiscal (Lei Complementar n. 101/2000) e a eficiência da gestão no município. Já a adoção do sistema apostilado $\mathrm{COC},{ }^{2}$ citado na matéria como indutor da melhoria, deuse apenas em $2007 .{ }^{3}$

Levantamento preliminar junto ao total dos municípios paulistas indicou que, no período de 1994 a 2006, dos 645 municípios, 161 informaram adotar ou já ter adquirido, neste período, "sistema apostilado" para a educação infantil e ensino fundamental, conforme 
especificado no Quadro 1. Ressalta-se que a pesquisa indica o aumento desse número para os anos posteriores.

\section{Quadro 1}

Municípios paulistas que declararam ter adquirido algum sistema apostilado de ensino no período de 1994 a 2007

\begin{tabular}{|l|c|c|}
\hline Município/porte & $\begin{array}{c}\text { Número total de } \\
\text { municípios: estado } \\
\text { de São Paulo }\end{array}$ & $\begin{array}{c}\text { Total de municípios que } \\
\text { declararam adotar algum } \\
\text { "sistema de ensino" }\end{array}$ \\
\hline $\begin{array}{l}\text { Municípios muito pequenos: } \\
\text { até 10.000 habitantes }\end{array}$ & 295 & 79 \\
\hline $\begin{array}{l}\text { Municípios pequenos: de 10.001 } \\
\text { a 50.000 mil habitantes }\end{array}$ & 234 & 71 \\
\hline $\begin{array}{l}\text { Municípios médios: de 50.001 a } \\
100.000 \text { habitantes }\end{array}$ & 54 & 05 \\
\hline $\begin{array}{l}\text { Municípios grandes: de 100.001 } \\
\text { a 500.000 habitantes }\end{array}$ & 54 & 06 \\
\hline $\begin{array}{l}\text { Municípios muito grandes: } \\
\text { mais de 500.001 habitantes }\end{array}$ & 8 & -- \\
\hline Total & 645 & 161 \\
\hline
\end{tabular}

Fonte: Elaborado pelas autoras.

Este quadro nos permite afirmar que um número significativo de municípios paulistas fez opção pela compra de sistemas apostilados de ensino. Até o ano de 2007, 154 municípios declararam manter a parceria. Em sua maioria, são municípios de pequeno porte que, na década de 1990, assumiram responsabilidades para com a oferta do nível obrigatório de ensino, para as quais, provavelmente, não estavam preparados. Tal situação parece confirmar a hipótese de que os pequenos municípios possuem condições mais adversas, do ponto de vista político e operacional para a oferta educacional. Complementarmente, tendem a ser mais permeáveis à pressão das empresas privadas, tendo em vista que a constituição da esfera pública em tais situações tende a ser mais frágil, aproximando-se o privado do público de maneira mais cotidiana e informal. Nestas circunstâncias, as relações se dão muitas 
Uma modalidade peculiar de privatização da educação pública...

vezes de maneira pessoalizada e regidas pelo clientelismo, condição na qual a filiação partidária é quase irrelevante (Holanda, 1971).

$\mathrm{Na}$ falta de efetivas diferenças político-partidárias locais, são as medidas governamentais com certa visibilidade que se convertem em diferenciais nas disputas eleitorais: a aquisição do sistema de apostilas de hoje concorre com a construção da praça ou do coreto de outrora.

O mapeamento realizado permite afirmar que a empresa responsável pelo maior número de contratos com municípios paulistas é o COC, instituição oriunda de Ribeirão Preto, no interior do estado, seguida pelo Positivo, pelo Objetivo e pelo OPET. O Objetivo e o coc são empresas paulistas, enquanto as duas outras são paranaenses. Além dessas, mais de uma dezena de outras empresas disputam o mercado aberto pela possibilidade de negócios com o poder público. Disputa que pode ser considerada acirrada, tendo em vista que as matrículas no setor privado se mantêm praticamente estagnadas, desde o começo dos anos de 1990 , em cerca de $10 \%$ do total de matrículas do ensino fundamental, o que gera a necessidade de disputa de novos "mercados" para a expansão das atividades destas empresas (MEC/INEP, Sinopses Estatísticas - 1993/2007).

Sistemas apostilados de ensino e a lógica do setor privado na oferta de educação pública: motivações e limites

A "cesta" que compõe os contratos firmados entre as prefeituras municipais e a iniciativa privada é integrada por atividades tradicionalmente desenvolvidas pelas equipes pedagógicas dos órgãos da administração pública e das escolas: formação continuada de educadores, efetivo acompanhamento das atividades docentes; investimento na produção e distribuição de materiais didáticos aos alunos; processos de avaliação externa e interna, entre as principais encontradas. Por essa razão, para além dos problemas pedagógicos derivados da adoção de material instrucional, em alguns casos desde a pré-escola, o que é importante destacar é o fato de que as empresas privadas passam, ao vender os chamados "sistemas de ensino", a interferir na gestão do próprio sistema escolar público local. Cabe salientar que a relação da empresa privada com a educação pública merece atenção destacada, tendo em vista a constatação dos seguintes aspectos: falta de controle social ou 
técnico, fragilidade conceitual e pedagógica dos materiais e serviços comprados pelos municípios, duplo pagamento pelo mesmo serviço, vinculação do direito à qualidade de ensino submetida à lógica do lucro e padronização/homogeneização de conteúdos e currículos escolares como parâmetro de qualidade.

O conjunto desses aspectos mencionados materializa-se de maneira frequentemente combinada. Todavia, para reflexão mais acurada, buscamos isolá-los num esforço para considerarmos as implicações de maneira mais completa possível.

\section{Falta de controle social ou técnico}

Destacamos neste subitem que, sobre o material didático produzido pelas instituições privadas, não incide ou incide muito limitadamente qualquer forma de controle social ou técnico. Em São Paulo, apenas em 2007, o Tribunal de Contas do Estado de São Paulo (TCE) passou a exigir processo licitatório para a aquisição dos sistemas apostilados. Até então, diversos municípios firmaram seus contratos, valendo-se de duas possibilidades: a primeira relativa ao artigo 25 , inciso I, da Lei que rege as licitações (Lei n. 8.666/93), segundo o qual a exclusividade de materiais, equipamentos ou gêneros desobriga a administração pública da licitação; a segunda possibilidade relaciona-se ao artigo 13 da mesma Lei, que trata de contratação de "serviços técnicos", o que inclui, segundo o referido artigo, o "treinamento e aperfeiçoamento de pessoal" (Silveira, 2008).

De acordo com Silveira, as duas possibilidades apresentam equívocos, uma vez que as apostilas de ensino não podem ser compreendidas como exclusividade de nenhuma empresa e podem ser produzidas por diferentes editoras ou grupos; em relação à segunda possibilidade, a autora afirma que, sendo o serviço técnico oferecido juntamente com material didático, não se caracteriza o previsto no artigo 13 da Lei n. 8.666/93 (Silveira, 2008), podendo, portanto, ser discutida juridicamente a sua utilização.

Além disso, os depoimentos obtidos nas entrevistas realizadas por ocasião da pesquisa de campo indicaram serem essas aquisições opção do Executivo e, na maioria das vezes, exclusivas do próprio prefeito. Poucos sãos os Conselhos Municipais de Educação que se posicionam 
Uma modalidade peculiar de privatização da educação pública...

sobre essa decisão, enquanto os Conselhos do FUNDEF e FUNDEB, quando muito, acompanham a prestação de contas e não opinam sobre a decisão já tomada pelo Executivo. Trata-se, portanto, de um retrocesso em relação à possibilidade de controle social sobre a implantação de políticas públicas previsto pela Constituição Federal de 1988.

\section{Fragilidade conceitual e pedagógica dos materiais e serviços comprados pelos municípios}

A segunda razão para redobrarmos a atenção às investidas da iniciativa privada relaciona-se diretamente aos itens que compóem os "sistemas", ou seja, ao material e ao serviço em si, tendo em vista a frequência com que Comissóes Parlamentares de Inquérito de Câmaras Municipais, os especialistas da educação ou o Ministério público têm questionado a qualidade e a pertinência do material comprado por distintas prefeituras.

Essa baixa qualidade pode estar relacionada, em parte, ao fato das empresas oferecerem aos municípios materiais distintos daqueles que elaboram para suas próprias escolas ou para as escolas privadas que franqueiam seu material. Trata-se de ofertar às escolas públicas um material de menor custo e que não faça frente àqueles existentes nas escolas privadas do município, uma vez que, se assim fosse, poderia haver um relativo êxodo das matrículas para o setor público, estabelecendo-se, ineditamente, uma concorrência intra-serviços oferecidos pela mesma empresa.

As empresas com maior presença junto aos municípios são conhecidas como Positivo, COC e Objetivo. Estas três empresas têm trajetórias semelhantes: originaram-se de cursinhos pré-vestibulares bem sucedidos, no sentido de conseguirem aprovar parte de seus alunos em cursos superiores de alta disputa no país, depois criaram escolas próprias que foram ampliadas em vários estados brasileiros por meio de franquias para redes privadas e, mais recentemente, para as redes públicas. Para este caso, criaram no seu interior estruturas, serviços e produtos específicos para os "clientes" públicos, sendo que, em algumas delas, foram criados departamentos especiais somente para viabilizar a realização jurídica destes contratos.

\section{Duplo pagamento pelo mesmo serviço}

Outra razão pela qual deveríamos ficar atentos à aquisição dos sistemas de ensino privados pelo setor público é o fato de que a população 
paga duplamente por materiais didáticos utilizados nas escolas públicas. Isto porque, atualmente, o governo federal executa três programas relacionados à distribuição de livros didáticos: $\mathrm{O}$ Programa Nacional do Livro Didático (PNLD), iniciado em 1989; o Programa Nacional do Livro Didático para o Ensino Médio (PNLEM), implantando em 2004, e o Programa Nacional do Livro Didático para a Alfabetização de Jovens e Adultos (PNLA), iniciado em 2007 (disponível em: <www.fnde.gov.br/home/ index.jsp?arquivo=livro_didatico.HTML $>$ ).

Apesar de muitos depoimentos de dirigentes municipais de Educação apontarem como principal motivação para a compra do sistema de ensino privado a baixa eficiência e problemas na distribuição dos livros destes programas federais, o fato é que, quando um município faz a opção por um sistema de ensino privado, há um duplo pagamento por materiais didáticos. A população já remunera empresas privadas do setor editorial, triadas por avaliação técnica para a produção de livros didáticos que integram os programas federais e cujo acervo está disponível gratuitamente às redes municipais de ensino. Os recursos que sustentam o PNLD são oriundos de orçamento do Ministério de Educação (MEC) destinado ao Fundo Nacional de Desenvolvimento da Educação (FNDE). A compra de materiais apostilados é efetuada com percentual dos recursos constitucionalmente vinculados à Manutenção e Desenvolvimento do Ensino, que poderiam ser destinados a outros aspectos das atividades pedagógicas para melhoria da educação local.

\section{Submissão do direito à qualidade do ensino à lógica do lucro}

$\mathrm{O}$ quarto aspecto que nos tem mobilizado a investigar essa nova investida do privado sobre o público refere-se ao fato de que, em se tratando do direito a um ensino de qualidade para todos na educação básica, assegurado pela legislação e fruto de pressão e reivindicação histórica de inúmeras entidades científicas, sindicais e populares, parecenos temerário delegar a consecução deste direito a empresas privadas, cujo objetivo primeiro é o lucro.

$\mathrm{Na}$ ausência de regulações claras, a educação pública vem sendo incorporada às estratégias de ampliação e concentração do capital privado da área educacional. Neste campo, como em qualquer esfera da sociedade capitalista, a lógica do capital é a de sua reprodução ampliada. 
Uma modalidade peculiar de privatização da educação pública...

Parece-nos que a tendência verificada em São Paulo até o começo do século XXI era a de que a ampliação do capital no campo educacional mantinha-se restrita ao próprio âmbito do setor privado. Até então, a opção estratégica do grande capital na educação básica se limitava à ampliação de seu mercado, por meio da incorporação de concorrentes de menor porte. Com isso, generalizou-se pelo estado de São Paulo a transformação de determinados colégios, em geral oriundos de cursos livres pré-vestibulares, em verdadeiras redes privadas de ensino, com níveis e etapas diversas de ensino, que se apresentam como "sistemas de ensino" concorrentes (Adrião, 2008).

Posteriormente, sem, contudo, se constituir em estratégia substitutiva, ganhou corpo a transformação de escolas privadas de menor porte ou experiência em franquias das grandes redes privadas de ensino. Em outras palavras, não se fazia mais necessário, ao grande capital, a aquisição do patrimônio físico das concorrentes e, com ele, de seus custos. Bastava assegurar a compra reeditada anualmente dos serviços oferecidos pelas redes: a terceirização do processo pedagógico se instalava.

É como movimento mais recente deste mesmo capital que percebemos a venda das apostilas/sistemas às redes públicas. Parece-nos que a busca por novos mercados é, da perspectiva do setor privado, o fator mobilizador de tais redes.

\section{A padronização/homogeneização de conteúdos e currículos escolares como parâmetro de qualidade}

A tentativa de padronização dos projetos pedagógicos e do trabalho realizado nas escolas é a principal justificativa dos dirigentes municipais de Educação para a realização de parcerias com sistemas de ensino privados. Buscam instaurar nas redes municipais uniformidade nos processos pedagógicos, alegando evitar "desigualdades" entre as escolas. Se tal motivação revela uma preocupação com a possibilidade de que ações diferenciadas gerem qualidade também diferenciada, por outro lado, incide sobre a autonomia de escolas e docentes frente à organização do trabalho pedagógico ao retirar-lhes, como assegura a LDB, a possibilidade de organizarem suas práticas a partir de necessidades locais ou iniciativas próprias. 
A padronização como forma de garantir identidade à rede municipa $l^{4}$ foi alegada por gestores de municípios que absorveram escolas pertencentes à rede estadual de ensino, uma vez que o processo de municipalização de escolas estaduais pressupõe a incorporação de profissionais e instituiçóes com trajetórias e experiências diferenciadas. A opção pela parceria apresenta-se como alternativa rápida a pretendidos ajustes nos processos de trabalho.

A precariedade técnico-operacional encontrada nos municípios, frente às suas responsabilidades para com a oferta de educação básica, parece estar no cerne dessa busca de qualidade por meio da padronização. Os dirigentes municipais entrevistados reconhecem limites de natureza técnico-pedagógica para se instituir um ensino de qualidade, tais como ausência de um quadro técnico qualificado para oferecer suporte ao trabalho desenvolvido nas unidades escolares, ou, ainda, precariedades na formação docente para as quais a alternativa seria o oferecimento de materiais apostilados, além de assessoria promovida pela instituição privada produtora do material. Transfere-se, assim, ao setor privado a gestão do processo pedagógico de toda a rede de ensino, aderindo-se a um "padrão de qualidade" estabelecido no âmbito do mercado.

As instituições privadas que oferecem os sistemas de ensino, com algumas exceçôes e variaçôes, tendem não só a determinar os conteúdos a serem desenvolvidos pelos professores, mas também os tempos de trabalho, as rotinas e a metodologia de ensino. Também a assessoria prestada, com variações de regularidade e de práticas, atua monitorando a implementação do material comprado pela municipalidade.

Sobre a possibilidade de os professores apresentarem resistência ao sistema apostilado e à consequente padronização de suas práticas, um dos gestores entrevistados observa que, exceto em situaçôes relativas a divergências políticas, os professores tendem a resistir apenas ao perceberem que seu trabalho sofrerá maior controle. A padronização, ainda, é "vendida" como uma possibilidade das famílias aumentarem o controle sobre o trabalho docente.

O pretendido pelo gestor municipal, neste caso, parece ser a homogeneização de condutas e práticas, desconsiderando que as escolas, embora regidas por normalizações gerais, são grupos sociais específicos em função dos sujeitos que nela atuam (Candido, 1984). 
Uma modalidade peculiar de privatização da educação pública...

\section{Considerações finais}

Segundo as informações coletadas nos estudos de casos, há, por parte dos gestores municipais, a recorrência a duas justificativas "pedagógicas" para a realização de parcerias com o objetivo de compra de sistemas de ensino: a padronização da qualidade do ensino, por meio da homogeneização dos projetos pedagógicos, e a construção de uma identidade para a educação municipal por meio dessa homogeneização. $\mathrm{O}$ modelo é um arremedo do proposto pelo e para o setor privado. A causa: a municipalização acelerada e sem pré-requisitos do ensino fundamental.

A padronização, tendo em vista a qualidade, é justificada pelo gestor quando este reconhece, ou afirma assim ser, a incapacidade do município promover açōes com vistas a qualificar o ensino e pressupóe a adoção de um único referencial pedagógico capaz de prever condutas, prescrever atividades e propor tempos unificados para o trato com o conteúdo. Neste caso, a recorrência ao sucesso do setor privado em atingir suas metas é o recurso apresentado.

Não há mençôes às desigualdades sociais, culturais e econômicas existentes e às diferenças inevitáveis entre as escolas e seus atores: é a supervalorização dos meios, alienados de fins desejados. Estamos de volta ao tecnicismo dos anos de 1970, com a diferença de agora os meios mais eficazes e eficientes virem adjetivados: precisam ser privados.

$\mathrm{Na}$ ausência de debates com profissionais da própria administração pública ou com a população usuária, a opção pelas empresas parceiras expressa a lógica da centralização de poder nas mãos do prefeito municipal.

A busca de padronização da qualidade, ainda, desconsidera, por meio de ingerência externa, as especificidades existentes nas unidades de ensino, em uma tentativa de padronização do que sabidamente é diverso (Arroyo, 2004, 2000), inibindo a autonomia de profissionais na gestão da educação e na unidade escolar, cujas consequências para a tarefa educativa estão por ser analisadas.

Pudemos também, mediante os dados coletados, inferir que as parcerias entre o setor público e empresas privadas da área educacional indicam uma nova forma de reprodução do capital. A ampliação das 
empresas, através de fusões, ou a compra de pequenas instituições por outras de maior porte já não são mais estratégias suficientes e estes procedimentos vêm sendo substituídos pela busca de expansão em outro "nicho": os municípios.

Estes, por sua vez, agregam condiçóes para que o "privado se expanda para dentro do público", quer seja pela dificuldade ou impossibilidade deste último em constituir quadros e serviços que atendam às necessidades de suporte à oferta educacional, quer pelas frágeis iniciativas de colaboração entre os entes federados, quer seja, ainda, pela capacidade do setor privado em se apresentar como alternativa tentadora aos interesses das políticas locais. A ênfase em um ou outro fator não minimiza o indesejável resultado da equação.

Temos a considerar o fato de alguns dirigentes apontarem outros benefícios importantes como resultado da parceria. Estes se configurariam principalmente em ganhos eleitorais, uma vez que a população tenderia a identificar como indicador de qualidade educativa a vinculação da educação municipal a logotipos e marcas de escolas privadas. Em muitos casos, essa vinculação é associada a uma suposta democratização do acesso à educação de qualidade, uma vez que, aparentemente, são minimizadas as diferenças entre os mais ricos, que podem pagar pelos estudos, e os mais pobres, que precisam recorrer ao poder público. Ressalta-se a suposta superioridade atribuída ao setor privado, concepção que se coaduna à perspectiva apresentada pela administração gerencial, segundo a qual a expertise capaz de conferir agilidade e eficácia ao setor público se encontra no mercado e no seu poder emulador de competitividade.

A percepção dos gestores não escapa às instituições privadas. Em uma delas, um de seus coordenadores afirma, em depoimento, que os políticos municipais têm no sucesso da educação escolar um dos caminhos para "pavimentar suas carreiras políticas", razão pela qual a qualidade da educação privada ter-se tornado atrativa, sobretudo após a ampliação de responsabilidades para a esfera administrativa municipal.

As responsabilidades assumidas pelos municípios para com a oferta educacional, como pode ser observado na pesquisa, trazem a necessidade de reflexão apurada sobre as consequências decorrentes das novas formas de inserção da lógica privada na educação pública. 
Uma modalidade peculiar de privatização da educação pública...

Este artigo visa a contribuir para tal debate, buscando salientar os graves limites que motivaçôes advindas do mercado ou de interesses particulares no âmbito da gestão municipal podem trazer para a qualidade e a organização da escola pública.

Recebido e aprovado em agosto de 2009.

\section{Notas}

1. Pesquisa desenvolvida com financiamento da Fundação de Amparo à Pesquisa do Estado de São Paulo (FAPESP).

2. Trata-se de nome fantasia da empresa educacional Colégio "Osvaldo Cruz".

3. João Ernesto Nicoleti (2009), em estudo sobre 39 municípios paulistas com até 50 mil habitantes, verificou que, em sete deles, as metas previstas pelo Índice de Desenvolvimento da Educação Básica (IDEB) não foram atingidas. Entre esses, quatro faziam uso de sistemas apostilados e três não mantinham nenhum tipo de contrato com empresas privadas. Para o autor, se tomado o IDEB como parâmetro para aferição da qualidade de ensino, no caso estudado não se pode atribuir relevância aos sistemas apostilados para a melhoria dessa qualidade.

4. Identidade esta, conforme observamos anteriormente, fortemente vinculada às características da empresa privada parceira.

\section{Referências}

ADRIÃO, T. Considerações sobre a privatização da educação pública paulista: notas sobre o aumento das parcerias entre governos municipais e iniciativa privada. In: SouzA, C.G.; Ribeiro, P.R.M. (Org.). Política, gestão educacional e formação de educadores: contribuições iberoamericanas para a educação. Araraquara: Cultura Acadêmica; unEsP; Instituto de Estudios Latinoamericanos da Universidad de Alcala y He, 2008. v. 10, p. 32-45.

ADRIÃO, T.; BORGHI, R. Parcerias entre prefeituras e a esfera privada: estratégias privatizantes para a oferta da educação pública em São Paulo? In: Adriâo, T.; Peroni, V. (Org.). Público e privado na educação: novos elementos para o debate. São Paulo: Xamã, 2008. p. 99110 .

ADRIÃO, T.; PERONI, V. (Org.). O público e o privado na educação: interfaces entre Estado e sociedade. São Paulo: Xamã, 2005. 
ANTUNES, F. Reformas do Estado e da educação: o caso das escolas profissionais em Portugal. Revista Brasileira de Educação, Rio de Janeiro, n. 29, p. 40-51, maio/ago. 2005.

ARELARO, L.R.G. A municipalização do ensino no estado de São Paulo: antecedentes históricos e tendências. In: Oliveira, C. et al. Municipalização do ensino no Brasil: algumas leituras. Belo Horizonte: Autêntica, 1999. p. 61-89.

ARELARO, L.R.G. A não-transparência nas relações público-privadas: o caso das creches conveniadas. In: Adriâo, T.; Peroni, V. (Org.). Público e privado na educação: novos elementos para o debate. São Paulo: Xamã, 2008. p. 51-66.

ARROYO, M.G. Ofício de mestre: imagens e auto-imagens. 6. ed. Petrópolis: Vozes, 2002.

ARROYO, M.G. Imagens quebradas: trajetórias e tempos de alunos e mestres. Petrópolis: Vozes, 2004.

BARRETO, E.S.S. Descentralizar e redistribuir nos sistemas de ensino. Cadernos de Pesquisa, São Paulo, n. 95, p. 73-78, 1995.

BARRETO, E.S.S.; ARELARO, L.R.G. A municipalização do ensino de $1^{\circ}$ grau: tese controvertida. Em Aberto, Brasília, DF, v. 5, n. 29, p. 1-13, jan./mar. 1988.

BEZERRA, E. Parceria público-privada nos municipios de Brotas e Pirassununga: estratégias para a oferta do ensino? 2008. Dissertação (Mestrado) - Instituto de Biociências, Universidade Estadual Paulista, Rio Claro.

BRASIL. Lei n. 8666, de 21 de junho de 1993. Regulamenta o artigo 37, inciso XXI da Constituição Federal, institui normas para licitações e contratos da Administração Pública e dá outras providências. Diário Oficial da União, Brasília, DF, 22 jun. 1993.

BRASIL. Ministério da Educação. Instituto Nacional de Estudos e Pesquisas Educacionais Anísio Teixeira (INEP). Sinopses estatísticas de 1993 a 2007. Disponível em: <http//:www.mec gov.br>. Acesso em: 21 jun. 2009. 
Uma modalidade peculiar de privatização da educação pública...

BRESSER PEREIRA, L.C. Crise econômica e reforma do Estado no Brasil. São Paulo: Editora 34, 1996.

BRESSER PEREIRA, L.C.; SPINK, P.K. (Org). Reforma do Estado e administração pública gerencial. Rio de Janeiro: FGV, 1998.

CAFARDO, R.; IWASSO, S. 150 municípios paulistas adotam apostilas em escolas públicas. O Estado de S. Paulo [on-line], São Paulo, 13 abr. 2008. Disponível em: <http: //www.estado.com.br/editorias/ 2008/04/13/ger-1.93.7.20080413.1.1.xml>. Acesso em: 6 jul. 2008.

CAMPOS, M.M.M. As políticas públicas de educação infantil no contexto da nova legislação educacional brasileira. Educação em Debate, São Paulo, n. 1, p. 21-36, 1998.

CANDidO, A. A estrutura da escola. In: Pereira, L.; Foracchi, M.M. Educação e sociedade. 12. ed. São Paulo: Nacional, 1984. p. 107-128.

CORREA, B.C. A educação infantil. In: Oliveira, R.P.; Adriāo, T. (Org.). Organização do ensino no Brasil: níveis e modalidades na Constituição Federal e na LDB. 2. ed. São Paulo: Xamã, 2007. p. 13-30.

CURY, C.R.J. Políticas públicas: diretrizes e necessidades da educação básica. In: ENCONTRO DE EDUCAÇÃO DO OESTE PAULISTA, 3., 2001, Marília. Anais... Marília: Unesp, 2001. p.1-3.

CURY, C.R.J. O público e o privado na história da educação brasileira: concepções e práticas educativas. In: Lombardi, J.C.; JACONELI, M.R.M.; Silva. T.M. (Org.). O público e o privado na história da educação brasileira: concepções e práticas educativas. Campinas: Autores Associados, 2005.

CURY, C.R.J.; MARTINS, C.B. O positivismo e a educação no Brasil. In: Martins, C.B. (Org.). Diálogos entre o Brasil e a França: formação e cooperação acadêmica. Recife: Fundação Joaquim Nabuco, 2005. p. 37-52.

DRAIBE, S.M. Reforma do Estado e descentralização: a experiência recente da política brasileira de ensino fundamental. Cadernos de Pesquisa do NEPP, Campinas, v. 37, p. 4-32, 1998. 
DOURADO, L.F. Políticas e gestão da educação básica no Brasil: limites e perspectivas. Educação \& Sociedade, Campinas, v. 28, n. 100, p. 921-946, out. 2007.

FARAH, M.F.S. Parcerias, novos arranjos institucionais e políticas públicas no nível local de governo. Revista Brasileira de Administração Pública, Rio de Janeiro, v. 35, n. 1, p. 119-144, 2001.

GANZELI, P.; OLIVEIRA, C. O processo de municipalização do ensino fundamental, da primeira à quarta série, em Piracicaba. In: GiUbiLEI, S. (Org.). Descentralização, municipalização e políticas educativas. Campinas: Alínea, 2001. p. 93-138.

HOLANDA, S.B. Raízes do Brasil. Rio de Janeiro: José Olympio; INL/MEC, 1971.

KRAWCZYK, N.R. A construção social das políticas educacionais no Brasil e na América Latina. In: KRAWCZYK, N.R.; CAmpos, M.M.; Haddad, S. (Org.). O cenário educacional latino-americano no limiar do século XXI: reformas em debate. Campinas: Autores Associados, 2000. p. $1-11$.

LEHER, R. Reforma do Estado: o privado contra o público. Trabalho, Educação e Saúde, Rio de Janeiro, v. 1, n. 2, p. 203-228, 2003.

MARTINS, A.M. Uma análise da municipalização do ensino no estado de São Paulo. Caderno de Pesquisa, São Paulo, n. 120, p. 221-238, nov. 2003.

NICOLETI, J.E. Ensino apostilado na escola pública: tendência crescente nos municípios da região de São José do Rio Preto-SP. 2009. Dissertação (Mestrado) - Faculdade de Ciências e Letras, Universidade Estadual Paulista, Araraquara.

OliveIRA, C. et al. Municipalização do ensino no Brasil. Belo Horizonte: Autêntica, 1999.

OLIVEIRA, R.P. Reformas educativas no Brasil na década de 90. In: Catani, A.F.; Oliveira, R.P. (Org.). Reformas educacionais em Portugal e no Brasil. Belo Horizonte: Autêntica, 2000. p. 77-94.

PERONI, V. Política educacional e papel do Estado: no Brasil dos anos 1990. São Paulo: Xamã, 2003. 
Uma modalidade peculiar de privatização da educação pública...

SAVIANI, D. Educação brasileira: estrutura e sistema. 12. ed. Campinas: Autores Associados, 1997.

SILVEIRA, A.D. Algumas consideraçôes sobre as normas do processo de licitação pública, contratos e convênios. Rio Claro, 2008. p. 12. (mimeo.). SOUSA, S.Z.L.; PRIETO, R.G. A educação especial. In: Oliveira, R.P.; Adriâo, T. (Org.). Organização do ensino no Brasil: níveis e modalidades na Constituição Federal e na LDB. São Paulo: Xamã, 2007. p. 123-136.

VIEIRA, S.L. Política educacional em tempos de transição (1985-1995). Brasília, DF: Plano, 2000. 